University of Nebraska - Lincoln

DigitalCommons@University of Nebraska - Lincoln

Faculty Publications, Department of Psychology

Psychology, Department of

2008

\title{
Cue-Elicited Negative Affect in Impulsive Smokers
}

\author{
Neal Doran \\ University of California, San Diego \\ Jessica Werth Cook \\ University of Washington, jwcook@ctri.wisc.edu \\ Dennis E. McChargue \\ University of Nebraska-Lincoln, dmcchargue2@unl.edu \\ Mark G. Myers \\ University of California, San Diego, and Veterans Affairs, mgmyers@ucsd.edu \\ Bonnie Spring \\ Northwestern University
}

Follow this and additional works at: https://digitalcommons.unl.edu/psychfacpub

Part of the Psychiatry and Psychology Commons

Doran, Neal; Werth Cook, Jessica; McChargue, Dennis E.; Myers, Mark G.; and Spring, Bonnie, "Cue-Elicited Negative Affect in Impulsive Smokers" (2008). Faculty Publications, Department of Psychology. 371. https://digitalcommons.unl.edu/psychfacpub/371

This Article is brought to you for free and open access by the Psychology, Department of at DigitalCommons@University of Nebraska - Lincoln. It has been accepted for inclusion in Faculty Publications, Department of Psychology by an authorized administrator of DigitalCommons@University of Nebraska - Lincoln. 


\title{
Cue-Elicited Negative Affect in Impulsive Smokers
}

\author{
Neal Doran \\ University of California, San Diego \\ Dennis McChargue \\ University of Nebraska-Lincoln
}

\author{
Jessica Cook \\ Veterans Affairs Puget Sound Health Care System and \\ University of Washington \\ Mark Myers \\ University of California, San Diego, and Veterans Affairs \\ San Diego Health Care System
}

\author{
Bonnie Spring \\ Northwestern University
}

\begin{abstract}
Impulsivity is associated with cigarette smoking, but the nature of this relationship and the mechanisms that maintain it are relatively unknown. The relationship has often been thought to reflect appetitive processes, but research suggests that an affective pathway exists as well. The present study tested the effect of impulsivity on affective responses to an environmental smoking cue. Adult smokers $(N=62)$ were exposed to a neutral cue and a smoking cue in separate experimental sessions in a repeatedmeasures design. Mixed-effects regression analyses showed that larger postexposure increases in negative affect were associated with high scores on 2 facets of impulsivity: urgency, $t(179)=6.16, p<.001$, and sensation seeking, $t(179)=4.75, p<.001$. Heightened impulsivity was associated with lower levels of positive affect generally but not with positive affective responses to cue exposure. Findings provide support for the existence of a negative affective pathway linking impulsivity and cigarette smoking, and they suggest that this pathway may be specific to the urgency and sensation-seeking components of impulsivity.
\end{abstract}

Keywords: impulsivity, nicotine, negative affect

Although knowledge of the deleterious consequences of cigarette smoking is now widespread, recent estimates indicate that about one in five adults in the United States is a current smoker (Centers for Disease Control, 2005). Reports that the cessation rates observed in clinical trials during the past 2 decades are significantly lower than are those for the 2 preceding decades (Irvin \& Brandon, 2000; Irvin, Hendricks, \& Brandon, 2003) have led researchers to propose a "hardening hypothesis." While controversial (Warner \& Burns, 2003), this hypothesis posits that those who continue to smoke are more dependent on nicotine and have higher levels of comorbid psychopathology (Hughes \& Brandon, 2003). In other words, continuing smokers may possess

Neal Doran, Department of Psychiatry, University of California, San Diego; Jessica Cook, Veterans Affairs Puget Sound Health Care System and Department of Psychiatry, University of Washington; Dennis McChargue, Department of Psychology, University of Nebraska-Lincoln; Mark Myers, Department of Psychiatry, University of California, San Diego, and Veterans Affairs San Diego Health Care System; Bonnie Spring, Feinberg School of Medicine, Northwestern University.

This research was supported by American Heart Association Grant $0410025 Z$ to Neal Doran.

Correspondence concerning this article should be addressed to Neal Doran, Veterans Medical Research Foundation, Third Floor, Department of Psychiatry, University of California, San Diego, 3350 La Jolla Village Drive, San Diego, CA 92161. E-mail: nmdoran@ucsd.edu underlying psychological and biological characteristics that maintain smoking and inhibit cessation.

One such characteristic is impulsivity, which has recently received increasing attention in the literature (e.g., Mitchell, 2004). Previous research has suggested that impulsivity is associated with cigarette smoking (Geist \& Hermann, 1990; Jenks, 1992; Kassel, Shiffman, Gnys, Paty, \& Zettler-Segal, 1994; Williams, 1973) and that it may inhibit cessation (Doran, Spring, McChargue, Pergadia, \& Richmond, 2004). However, mechanisms that may explain this relationship remain largely untested. Additionally, the fact that multiple definitions of impulsivity exist in the literature (Evenden, 1999) renders comparative analysis difficult.

The propensity of more impulsive individuals for substance abuse has often been viewed as an appetitive process. Such individuals are thought to be hypersensitive to reward (Martin \& Potts, 2004) and to have difficulty in inhibiting a response to immediately rewarding stimuli (Arnett \& Newman, 2000). However, extant evidence also suggests the existence of a negative reinforcement pathway between impulsivity and substance use. For example, Emmons and Diener (1986) have shown that impulsive individuals may experience negative affect more frequently than do others. Additionally, impulsivity appears to be associated with a tendency to use drugs as a response to negative affect. Adolescents with high levels of both impulsivity (defined as acting without forethought) and neuroticism are more likely than are others to drink as a means of coping with negative affect (Cooper, Agocha, 
\& Sheldon, 2000), and teens high in behavioral undercontrol (a temperamental characteristic that reflects lack of premeditation, sensation seeking, and aggression; King \& Chassin, 2004) tend to consume more alcohol during bouts of negative affect than do others (Hussong \& Chassin, 1994). Individuals with high levels of behavioral undercontrol have also been found to expect (Mann, Chassin, \& Sher, 1987) and receive (Sher \& Levenson, 1982) greater stress reduction from alcohol consumption than do others.

We recently reported similar findings in smokers. In both studies, impulsivity was assessed with the Barratt Impulsiveness Scale (Patton, Stanford, \& Barratt, 1995), which defines impulsivity as a tendency to focus on present rather than future consequences of behavior, a lack of planning, quick decision making, and a tendency to become easily bored or restless. First, in a sample of undergraduate smokers, we found that impulsivity was positively associated with expectations of positive reinforcement and negative affect relief from smoking (Doran, McChargue, \& Cohen, 2007). The second study (Doran et al., 2006) suggested that heightened expectations of negative affect relief might be realistic. Following a negative mood induction, participants smoked either a nicotinized or a de-nicotinized cigarette in a repeated-measures design. Higher impulsivity was associated with greater postinduction reduction in self-reported negative affect after smoking a nicotinized cigarette but not after smoking a de-nicotinized cigarette.

Although evidence is somewhat limited, impulsivity has been linked to reactivity to drug cues. The use of the cue reactivity paradigm in substance abuse research is based on the idea that drug-associated environmental stimuli increase susceptibility to drug use (e.g., Baker, Morse, \& Sherman, 1987; Marlatt \& Gordon, 1985). Impulsivity has been shown to predict craving responses to drug cue exposure in opiate addicts (Powell, Bradley, \& Gray, 1992) and heavy drinkers (Kambouropoulos \& Staiger, 2001). We recently found that, in the present sample, impulsivity was associated with heightened craving reactivity to a smoking cue (Doran, Spring, \& McChargue, 2007).

Although fewer studies have examined affective reactivity to drug cues, cue exposure has been reported to increase negative affect in smokers (Hutchison et al., 1999; Tiffany, Cox, \& Elash, 2000). This effect may vary as a function of nicotine deprivation, so that more deprived smokers experience greater postexposure increases in negative affect (Payne, Smith, Sturges, \& Holleran, 1996). To the extent that specific affective states trigger smoking, cue-induced affect may be an important contributor to the relationship between cue exposure and subsequent use. Additionally, the impact of cue-induced affect on smoking behavior may be particularly important for impulsive smokers, who may be more prone to substance use during negative affective states.

As Mitchell (2004) has noted, the lack of a standard definition of impulsivity has made integration of the relatively few studies of the relationship between impulsivity and cigarette smoking more difficult. It has been suggested that the term is used to describe several related but distinct phenomena (e.g., disinhibition, difficulty delaying gratification, sensation seeking, lack of persistence) that may have different biological bases (Evenden, 1999). Whiteside and Lynam (2001) recently used factor analysis of several common impulsivity measures to develop the Urgency, Premeditation, Perseverance, and Sensation-Seeking Impulsive Behavior Scale (UPPS), which measures four aspects of impulsivity: ur- gency (the tendency to act impulsively as a means of reducing negative affect), lack of premeditation, lack of perseverance, and sensation seeking. It is plausible that these facets are distinct characteristics that produce similar behavior (i.e., acting without forethought) under different conditions (Whiteside, Lynam, Miller, \& Reynolds, 2005). Although the UPPS was initially developed with an undergraduate sample (Whiteside \& Lynam, 2001), it has been shown to differentiate control participants from pathological gamblers as well as from individuals diagnosed with borderline personality disorder and alcohol abuse in a community sample with a mean age of 40.6 years (Whiteside et al., 2005). The use of more comprehensive instruments, such as the UPPS, to assess impulsivity is important for clarification of the relationship between impulsivity and substance abuse. For example, impulsive individuals who tend to use substances to cope with negative affect may have particularly high levels of the urgency facet of impulsivity.

Our primary aim in the present study was to test the hypothesis that more impulsive smokers experience disproportionate changes in negative affect when they are exposed to an environmental smoking cue. To compare the hypothesized negative reinforcement pathway with the traditional conceptualization of substance abuse as an appetitive process among more impulsive individuals, we also assessed positive affect reactivity. Participants were exposed to a smoking cue and to a neutral cue in separate experimental sessions. It was expected that positive and negative affective responses to smoking cue exposure would be strongest among participants who reported low levels of perseverance and high levels of urgency. Individuals low in perseverance tend to have difficulty remaining in aversive situations (e.g., being exposed to a smoking cue but being unable to smoke). For those with high levels of urgency, who may be especially prone to smoking during aversive affective states, smoking cues may be more strongly associated with such states. Consequently, we hypothesized that participants who were low in perseverance and high in urgency would report greater increases in negative affect and greater decreases in positive affect following smoking cue exposure.

\section{Method}

\section{Sample}

Participants $(N=62,50 \%$ male) were regular smokers who were recruited via flyers posted in the community and were paid $\$ 70$ to attend one screening and two experimental sessions. They were between 18 and 65 years of age $(M=30.8$ years, $S D=10.8)$ and had smoked at least 15 cigarettes per day $(M=19.1, S D=$ $5.2)$ for the past year or more $(M=18.1$ years, $S D=9.9)$. The sample was diverse, with $51 \%$ identifying as Caucasian, $33 \%$ as African American, 9\% as Asian American, 4\% as Hispanic or Latino, and $2 \%$ as multiethnic. The majority of participants reported some higher education experience, with $43 \%$ having obtained a 4-year degree and $15 \%$ a 2 -year degree. An additional $13 \%$ had attended college without obtaining a degree, and the remaining $29 \%$ of the sample reported a high school education. Participants were moderately nicotine dependent, as indicated by an average score of $5.4(S D=1.9)$ on the Fagerström Test for Nicotine Dependence (FTND; Heatherton, Kozlowski, Frecker, \& Fagerström, 1991). Individuals who met criteria for any current 
Axis I disorder other than nicotine dependence or who currently used nicotine replacement therapy were excluded. Candidates were asked during telephone screening whether they were currently attempting to quit smoking; those who responded affirmatively were excluded from participation.

\section{Measures}

Impulsivity. At the screening session, participants completed the UPPS (Whiteside \& Lynam, 2001). The UPPS was derived from a factor analysis of commonly used self-report impulsivity scales by use of a varimax rotation. It is a 45 -item scale that contains four subscales: Urgency (e.g., "When I feel bad, I will often do things I later regret in order to make myself feel better now"); Premeditation (e.g., "My thinking is usually careful and purposeful"); Perseverance (e.g., "I tend to give up easily"); and Sensation Seeking (e.g., "I quite enjoy taking risks"). All subscales are scored such that higher values indicate greater impulsivity. The UPPS has excellent internal consistency, with Cronbach's alpha coefficients for the four subscales ranging from .82 to .91 . Pearson correlation coefficients among the UPPS subscales are modest (average $r=.22$ ), which suggests that the scales measure distinct facets of impulsivity (Whiteside \& Lynam, 2001). Internal consistency for UPPS subscales in the present sample ranged from .78 to .91 , and the average correlation between subscales was $r=.30$.

Affective state. Positive and negative affect were measured with the Positive and Negative Affect Scale (PANAS; Watson, Clark, \& Tellegen, 1988). This 20-item scale asks respondents to indicate the extent to which 20 words describe their current mood. The 10-item Positive Affect subscale includes items such as "enthusiastic," "excited," and "inspired," whereas the 10-item Negative Affect subscale includes items such as "hostile," "irritable," and "distressed." Cronbach's alpha values in the present study ranged from .82 to .88 for positive affect and from .75 to .87 for negative affect. Participants completed the PANAS at baseline of each experimental session and again immediately following each 5-min cue exposure.

Cigarette craving. We used the 10-item version of the Questionnaire of Smoking Urges (QSU-Brief; Cox, Tiffany, \& Christen, 2001) to assess craving. This self-report measure yields two factors: cravings anticipating pleasure (reward craving) and cravings anticipating relief from negative affect (relief craving). The QSU-Brief has been shown to have good construct validity and internal consistency (Cox et al., 2001). In the current sample, internal consistency ranged from .84 to .93 across measurements. The QSU-Brief was completed at baseline of each experimental session and again immediately after each cue exposure.

Smoking characteristics. At screening, we used the FTND (Heatherton et al., 1991) to assess nicotine dependence. The 6-item FTND scale sums behavioral characteristics that suggest nicotine dependence (e.g., time between waking and first cigarette). Scores range from 0 to 10 , with higher scores indicating higher levels of dependence. Additionally, at the screening session and both experimental sessions, we assessed expired carbon monoxide (CO) via ecolyzer (EC-50, Vitalograph Corporation, Lenexa, KS) to confirm self-reported smoking status. $\mathrm{CO}$ values of $8 \mathrm{ppm}$ or greater were considered to be consistent with regular smoking. Two participants had $\mathrm{CO}$ values of less than $8 \mathrm{ppm}$ at baseline of an experimental session. In both cases, the session was resched- uled and the participant was instructed to smoke his or her normal amount before the new session; both participants had $\mathrm{CO}$ values of at least $8 \mathrm{ppm}$ at baseline of the rescheduled session. Finally, at the beginning of each experimental session, participants reported the time at which they had last smoked. This datum was converted into the number of minutes between their last cigarette and the beginning of the experimental session. Time since last cigarette ranged from 5 to $540 \mathrm{~min}$, with a mean of $28.3 \mathrm{~min}(S D=67.1)$ and a median of $20 \mathrm{~min}$. One participant reported last smoking on the evening prior to both experimental sessions; the others had smoked within 90 min of the start of each session.

Axis I disorders. To assess whether potential participants met criteria for any current Axis I disorders, trained diagnosticians administered the Structured Clinical Interview for DSM-III-RNonpatient Edition (SCID-NP; Spitzer, Williams, Gibbon, \& First, 1992). A licensed clinical psychologist supervised interviewers to ensure reliability and accuracy of diagnoses. The SCID-NP has been shown to compare favorably with other methods of diagnostic assessment (Williams et al., 1992).

\section{Procedure}

Screening. Potential participants were initially screened by telephone. During the screening, they provided demographic and smoking information for an initial determination of eligibility, listened to a description of the study, and were encouraged to ask questions about participation. Candidates who remained eligible and interested following telephone screening were scheduled to come to the laboratory for a screening interview. Following the interview, participants provided written informed consent for study participation and completed the UPPS, as well as demographic and smoking history questionnaires. They were scheduled for two experimental sessions.

Experimental sessions. To maximize generalizability, we instructed participants to smoke as usual prior to experimental sessions, which were administered in counterbalanced order. Each 2-hr experimental session began between 8:00 a.m. and 10:00 a.m. At the beginning of each session, we analyzed the breath of participants for expired $\mathrm{CO}$ and recorded the time since their last cigarette. After participants had completed the PANAS and measures of cigarette craving, a 20-min rest period minimized the possibility of limited cue reactivity among those who had smoked immediately prior to the session. Participants were next exposed to either a smoking cue or a neutral cue, after which affect and craving were reassessed.

Cue exposure procedures were conducted in the same room as were other portions of the experimental sessions. A lab office approximately $2.7 \mathrm{~m} \times 3.7 \mathrm{~m}$, it contained a table at which participants sat, as well as a desk for the experimenter. Smoking materials not needed for a session were stored out of sight. The experimenter remained in the room while participants completed questionnaires but was not present during the rest period. Following the rest period, the experimenter returned and verbally instructed participants in the cue exposure procedure. Participants were then left alone in the room for the 5-min cue exposure. We used an air filtration system (Hastings Air Energy Control, New Berlin, WI) between experimental sessions to minimize the smell of smoke in the room. 
Cue exposure. The cue exposure procedure was adapted from the procedure described by Sayette and Hufford (1994). In the smoking cue condition, participants were shown a pack of their usual brand of cigarettes, a lighter, and an ashtray on the table in front of them. They were instructed to light a cigarette without touching it to their mouths and to hold the cigarette in their hand, without smoking it, for $5 \mathrm{~min}$. The neutral cue condition was identical, except that no smoking paraphernalia were present and participants held a roll of tape rather than a cigarette.

\section{Analytic Plan}

Positive and negative affect were assessed across the four assessments (baseline and postexposure in both cue conditions) via mixed-effects regression modeling. Because it included baseline values in the time-varying dependent variable, this approach accounted for any baseline differences in affect. The analyses were implemented via SAS PROC MIXED and utilized models with random intercepts, linear trends, and autoregressive errors. As recommended by Verbeke and Mohlenberghs (2000), this variance-covariance structure was chosen after comparison with several other potential structures.

The mixed-effects modeling approach has several advantages over other methods (e.g., repeated-measures analysis of variance; ANOVA). In particular, it allows for models that include both categorical and continuous predictor variables, as well as timevarying and time-invariant predictor and outcome variables, in a single model. Additionally, mixed-effects regression models with autoregressive errors are based on assumptions about correlations between repeated measures of a single variable that are likely to be more realistic. Whereas ANOVA assumes that all measurements of a repeated-measures variable are equally correlated, mixedeffects regression assumes that the strength of the correlation is dependent on the temporal proximity of the two measurements (Gibbons et al., 1993; Hedeker, Flay, \& Petraitis, 1996).

Age, nicotine dependence, phase (pre- vs. postexposure), and exposure condition were included as covariates in all analyses. In light of our previous work that showed a relationship between impulsivity and craving reactivity in this sample (Doran, Spring, et al., 2007), both cigarette craving subscales (Reward Craving and Relief Craving) were included as covariates. We hypothesized that, of the four facets of impulsivity assessed by the UPPS, perseverance and urgency would be most strongly related to change in affect following cue exposure. Consequently, the initial version of the primary model included the main effects of urgency, premeditation, perseverance, and sensation seeking, as well as their two- and three-way interactions with the phase and condition variables. Nonsignificant terms were removed from the model in a backwards manner. It should be noted that the interpretation of main effects in mixed-effects regression models is dependent on the interaction terms included in the model. More specifically, if an interaction is included in the model, the main effect of each variable in the interaction term reflects the main effect when all other variables in the interaction term equal zero (Hedeker \& Gibbons, 1997). For example, in a model that includes the main effect of urgency as well as its two- and three-way interactions with phase and condition, the main effect of urgency represents the effect when phase and condition equal zero (i.e., baseline in the neutral exposure condition). Consequently, main effects were in- terpreted only in the absence of significant interactions. We expected to find significant three-way interactions of impulsivity variables, particularly perseverance and urgency, with phase and condition. When significant three-way interactions were found, we stratified the data by exposure condition and tested the interactions between impulsivity variables and phase within each condition.

\section{Results}

\section{Preliminary Analyses}

Descriptive statistics for impulsivity and positive and negative affect variables are shown in Table 1. To determine appropriate covariates, we assessed the relationships of various demographic and smoking characteristics with impulsivity and affect. Variables that were not significantly associated with impulsivity variables or postexposure change in affect included gender, education, time since last cigarette, and daily cigarette consumption. Age was found to be associated with sensation seeking $(r=-0.44, p<$ $.001)$, and nicotine dependence was significantly correlated with negative affect following cigarette cue exposure $(r=.30, p=$ .017). Consequently, age and nicotine dependence were included as covariates in all subsequent analyses. Paired-samples $t$ tests indicated that baseline negative affect did not vary across exposure condition, $t(61)=0.33, p=.741$. Negative affect increased significantly after cigarette cue exposure, $t(61)=7.93, p<.001$, but not after the neutral cue exposure, $t(61)=0.59, p=.556$. A repeated-measures ANOVA showed that postexposure change in negative affect was not related to the order in which experimental sessions occurred. Baseline positive affect did not vary by cue condition, $t(61)=1.65, p=.103$. Postexposure positive affect scores were significantly lower than were baseline scores in the cigarette cue condition, $t(61)=2.10, p=.039$, but not in the neutral cue condition, $t(61)=0.30, p=.763$. There was no effect of session order on postexposure change in positive affect.

\section{Primary Analyses}

The final model for negative affect is shown in Table 2. Neither age nor nicotine dependence significantly predicted negative affect. Increased relief craving was associated with higher levels of

Table 1

Descriptive Statistics for Predictor and Outcome Variables

\begin{tabular}{lcc}
\hline \multicolumn{1}{c}{ Variable } & $M$ & $S D$ \\
\hline Urgency & 29.01 & 6.81 \\
Premeditation & 27.73 & 6.61 \\
Perseverance & 28.65 & 5.27 \\
Sensation seeking & 29.45 & 6.68 \\
Negative affect & & \\
$\quad$ Baseline neutral & 14.53 & 4.66 \\
$\quad$ Postexposure neutral & 14.70 & 5.36 \\
$\quad$ Baseline cigarette & 14.37 & 5.28 \\
$\quad$ Postexposure cigarette & 19.73 & 8.00 \\
Positive affect & & \\
$\quad$ Baseline neutral & 30.66 & 8.27 \\
Postexposure neutral & 30.56 & 7.03 \\
$\quad$ Baseline cigarette & 31.42 & 8.86 \\
$\quad$ Postexposure cigarette & 30.32 & \\
\hline
\end{tabular}


Table 2

Mixed-Effects Regression Model Predicting Negative Affect

\begin{tabular}{lrrrr}
\hline \multicolumn{1}{c}{ Variable } & $B$ & $S E$ & $t$ & $p$ \\
\hline Covariate & & & & \\
Age & 0.12 & 0.14 & 0.86 & .392 \\
Nicotine dependence & 0.14 & 0.14 & 0.99 & .323 \\
Reward craving & 0.03 & 0.05 & 0.61 & .541 \\
Relief craving & 0.29 & 0.06 & 4.78 & $<.001$ \\
Effect of interest & & & & \\
Phase & 4.27 & 2.75 & 1.55 & .123 \\
Exposure condition & -0.43 & 3.90 & -0.11 & .913 \\
Phase $\times$ Condition & 5.82 & 5.49 & 1.06 & .290 \\
Premeditation & 0.11 & 0.13 & 0.79 & .433 \\
Perseverance & 0.26 & 0.11 & 2.38 & .018 \\
Urgency & 0.33 & 0.18 & 1.82 & .070 \\
Urgency $\times$ Phase & 0.03 & 0.09 & 0.31 & .760 \\
Urgency $\times$ Condition & -0.10 & 0.09 & -1.06 & .289 \\
Urgency $\times$ Phase $\times$ Condition & 0.28 & 0.05 & 6.16 & $<.001$ \\
Sensation seeking & 0.11 & 0.10 & 1.09 & .279 \\
Sensation Seeking $\times$ Phase & -0.03 & 0.07 & -0.43 & .665 \\
Sensation Seeking $\times$ Condition & 0.10 & 0.07 & 1.48 & .141 \\
Sensation Seeking $\times$ Phase $\times$ Condition & 0.26 & 0.06 & 4.75 & $<.001$ \\
\hline
\end{tabular}

negative affect, $t(179)=4.78, p<.001$, but the relationship between negative affect and reward craving was not significant. Neither relationship varied as a function of phase or condition. Premeditation was unrelated to negative affect. The significant main effect of perseverance, $t(179)=2.38, p=.018$, indicated that those who reported lower levels of perseverance also reported higher levels of negative affect, regardless of phase or condition. The two- and three-way interactions between perseverance and the condition and phase variables were all nonsignificant. This result indicated that perseverance was not associated with negative affective response to cue exposure. The Urgency $\times$ Phase $\times$ Condition interaction was significant, $t(179)=6.16, p<.001$, as was the Sensation Seeking $\times$ Phase $\times$ Condition interaction, $t(179)=$ $4.75, p<.001$, which indicated that negative affective response to cue exposure varied as a function of both urgency and sensation seeking.

To interpret the three-way interactions, we stratified the data by exposure condition and refit the model for each condition sepa- rately. In the neutral cue condition, the Urgency $\times$ Phase term, $t(59)=1.06, p=.293$, and the Sensation Seeking $\times$ Phase term, $t(59)=0.78, p=.441$, were nonsignificant. However, both Urgency $\times$ Phase, $t(59)=3.11, p=.003$, and Sensation Seeking $\times$ Phase, $t(59)=2.38, p=.021$, were significant in the cigarette cue condition. To depict these interactions graphically, we stratified the data by condition and calculated Pearson $r$ correlation coefficients between urgency and negative affect (Figure 1) and sensation seeking and negative affect (Figure 2) at each measurement point (pre- and postexposure in each condition). Using the procedures described by Steiger (1980) for dependent samples, we compared pre- and postexposure correlations. The association between urgency and negative affect remained stable in the neutral cue condition (baseline $r=.30, p=.017$; postexposure $r=.32, p=.011 ; z=-0.36, p=.722$ ) but increased significantly following exposure to the cigarette cue (baseline $r=$ $.28, p=.031$; postexposure $r=.47, p<.001 ; z=-2.80, p=$ .005). The relationship between sensation seeking and negative affect was similar at both points in the neutral cue condition (baseline $r=.14, p=.312$; postexposure $r=.12, p=.371 ; z=$ $0.34, p=.733$ ) but was marginally stronger after cue exposure in the cigarette cue condition (baseline $r=.16, p=.238$; postexposure $r=.29, p=.021 ; z=-1.79, p=.073)$. In other words, urgency was more strongly related to postexposure negative affect than to preexposure negative affect in the cigarette cue condition but not in the neutral cue condition. Sensation seeking showed a similar but weaker pattern.

The final model for positive affect is shown in Table 3. Age, reward craving, relief craving, and exposure condition were unrelated to positive affect. There was a significant relationship between positive affect and nicotine dependence, $t(179)=-2.31$, $p=.022$, such that more dependent participants reported lower levels of positive affect across all four assessments. Although sensation seeking and urgency were not associated with positive affect, there was a significant main effect of perseverance, $t(179)=-2.15, p=.033$, such that participants who reported lower levels of perseverance tended to report lower levels of positive affect. However, perseverance did not predict change in positive affect as a function of cue exposure. Finally, there was a significant Premeditation $\times$ Phase interaction, $t(179)=-2.43$,

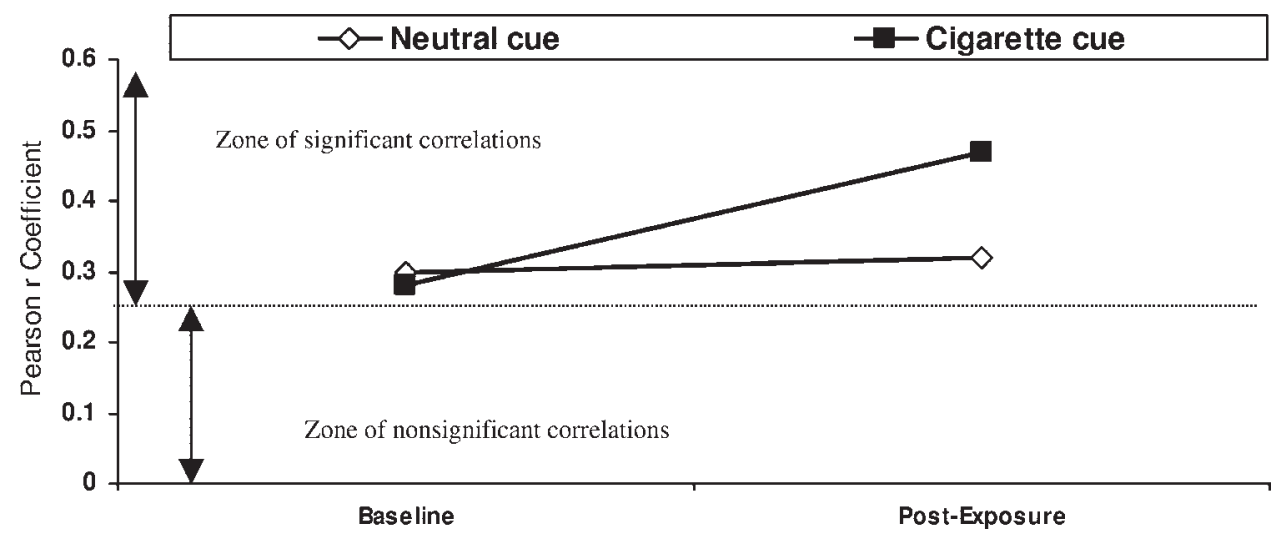

Figure 1. Correlations between urgency and negative affect by phase and condition. Points above the horizontal line indicate $p<.05$. 


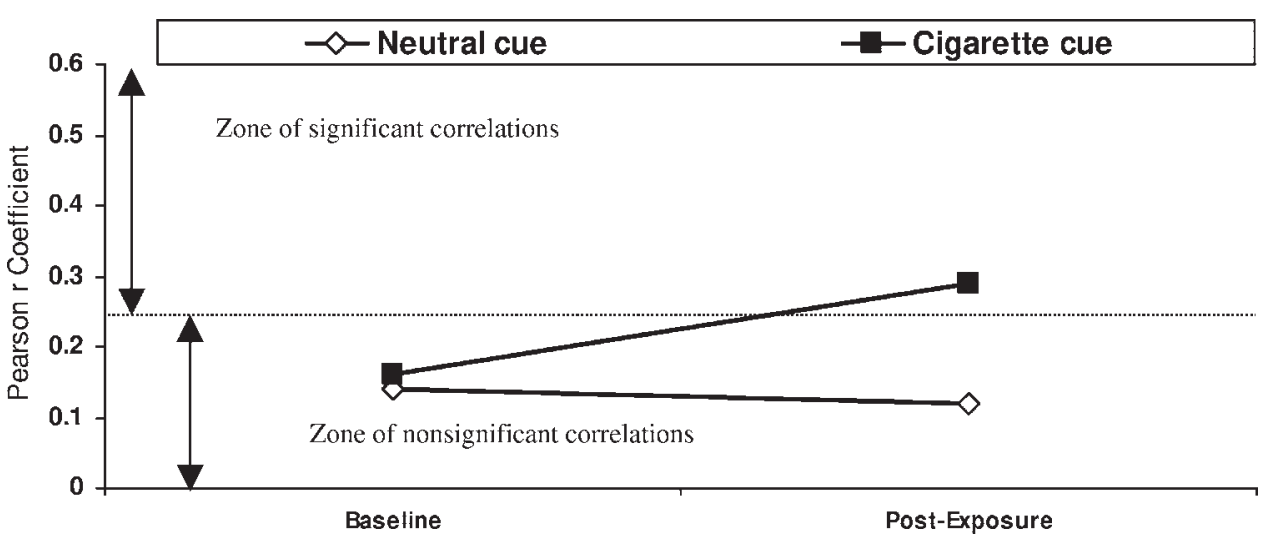

Figure 2. Correlations between sensation seeking and negative affect by phase and condition. Points above the horizontal line indicate $p<.05$.

$p=.016$, which indicated that higher premeditation scores (i.e., less premeditation) were associated with lower levels of postexposure positive affect in both conditions.

\section{Discussion}

We found that a larger negative affective response to a smoking cue was associated with higher levels of the urgency and sensation-seeking components of impulsivity but was unrelated to the lack of premeditation or lack of perseverance components. That is, those who reported a tendency to act impulsively in order to alleviate negative affect or an inclination toward exciting, risky behaviors also experienced more aversive reactions in the presence of a lit cigarette when they were unable to smoke. Additionally, whereas the lack of perseverance and urgency components predicted lower levels of positive affect generally, impulsivity components did not predict a differential positive affective response to a smoking cue.

Urgency was a significant predictor of negative affect at each measurement point, with a notable increase in the strength of the relationship after smoking cue exposure. In other words, smokers high in urgency appeared to be generally prone to higher levels of negative affect. Such individuals tend to respond to aversive circumstances without considering the consequences of their re-

Table 3

Mixed-Effects Regression Model Predicting Positive Affect

\begin{tabular}{lrrrr}
\hline \multicolumn{1}{c}{ Variable } & $B$ & $S E$ & $t$ & $p$ \\
\hline Covariate & & & & \\
$\quad$ Age & -0.94 & 1.77 & -0.53 & .598 \\
Nicotine dependence & -0.81 & 0.35 & -2.31 & .022 \\
Reward craving & -0.64 & 0.43 & -1.51 & .134 \\
$\quad$ Relief craving & -0.19 & 0.15 & 1.33 & .198 \\
Effect of interest & & & & \\
Phase & -4.49 & 1.84 & -2.45 & .015 \\
Exposure condition & 0.82 & 0.55 & 1.48 & .140 \\
Premeditation & 0.04 & 0.22 & 0.19 & .850 \\
Premeditation $\times$ Phase & -0.15 & 0.06 & -2.43 & .016 \\
Perseverance & -0.56 & 0.26 & -2.15 & .033 \\
$\quad$ Urgency & -0.27 & 0.17 & 1.53 & .128 \\
Sensation seeking & -0.20 & 0.14 & -1.37 & .173 \\
\hline
\end{tabular}

sponses (Whiteside \& Lynam, 2001). Therefore, they may experience more deleterious consequences from their behavior than do others. The present findings suggest that environmental smoking cues further heighten negative affect for smokers who are high in urgency. It is possible that this affective reactivity could lead such individuals to be more likely than others to smoke in response to environmental cues, though this possibility was not assessed in the current study.

Somewhat surprisingly, whereas sensation seeking was not related to negative affect at other measurement points, participants higher in sensation seeking reported higher levels of negative affect following exposure to the smoking cue. Sensation seeking is generally thought to be associated with positive affect (e.g., Zuckerman, Joireman, Kraft, \& Kuhlman, 1999). However, some evidence suggests that it may also be linked with negative affective states, such as anger and hostility (Joireman, Anderson, \& Strathman, 2003). Additionally, Zelenski and Larsen (1999) reported that a positive mood induction actually elicited increased negative affect among individuals with high levels of sensation seeking. Most interestingly, Carver (2004) reported that high levels of fun seeking, which is similar to sensation seeking, predicted increased frustration and sadness when individuals were unable to obtain an expected reward. The present study was similar in that, although participants did not necessarily expect to be able to smoke, they were unable to do so while in the presence of the smoking cue. It is plausible that individuals with high levels of sensation seeking are accustomed to engaging in approach behavior when cued that a reward is available and that they experience increased negative affect when they are unable to do so.

Another potential explanation for the current findings is derived from research on classical conditioning in addiction (e.g., Siegel, 1999, 2005). This work has shown that drug cues become paired with direct drug effects and function as conditional stimuli. After pairing is established, cues elicit compensatory responses that counteract drug effects and contribute to the development of drug tolerance. Given that more impulsive smokers may both expect (Doran, McChargue, et al., 2007) and receive (Doran et al., 2006) relief from negative affect by smoking, more intense negative affect following smoking cue exposure may reflect a compensatory response to the anticipated direct effect of smoking. Such a 
compensatory response could plausibly be a function of high scores on the urgency facet of impulsivity or be particularly strong among smokers with high levels of urgency, who may be particularly likely to smoke with the intention of alleviating negative affect.

Consistent with our hypotheses, premeditation was not a predictor of negative affective response to cue exposure. Premeditation could be hypothesized to be inversely associated with chronic negative affect in the same manner as is urgency (i.e., lack of forethought leads to more frequent negative consequences), but it has not been thought to be related to acute affect. However, contrary to our predictions, perseverance was also unrelated to negative affective reactivity to smoking cue exposure. We expected that being cued to smoke but not being allowed to do so would constitute an aversive and unavoidable situation that would elicit negative affect in those with lower levels of perseverance. There are two potential explanations for the failure to confirm this hypothesis. First, analyses showed a main effect of perseverance on negative affect, regardless of phase or cue condition. It is possible that participants who were lacking in perseverance found the laboratory tasks sufficiently aversive that they experienced high levels of negative affect throughout the experimental sessions. In that case, smoking cue exposure might not have been powerful enough to substantially increase the aversive nature of the situation. Alternatively, the laboratory sessions may have been fairly novel situations for most participants; as such, the sessions might have failed to induce negative affect among those individuals who reported lower levels of perseverance, because they were not experienced as boring or aversive.

Certain characteristics of the present study may limit interpretation of the findings. In particular, participants were in an artificial laboratory setting, which placed constraints on their range of possible responses to smoking cue exposure. For example, outside the laboratory, more impulsive smokers are often free to respond to cigarette cues by smoking immediately, which potentially limits any affective response. Consequently, these findings may be most representative of the experience of being exposed to a smoking cue in a setting where smoking is prohibited (e.g., in the workplace). However, it should be noted that such settings are unlikely to contain cues as powerful as is handling and lighting a cigarette without being able to smoke. Thus, the smoking cue may have elicited a level of frustration unrepresentative of the typical experience of environmental cues. It is possible that the relationship between impulsivity and negative affect in response to smoking cues observed here differs from what would be observed in a situation in which the cue produces less frustration. Finally, to increase generalizability outside the laboratory, we instructed participants to smoke as usual prior to experimental sessions and left time since last cigarette unstandardized. This design feature raises the possibility that reactivity to cue exposure might have been confounded with nicotine deprivation processes. Although deprivation was not explicitly assessed, as noted above, we did measure time since last cigarette prior to experimental sessions. The fact that this variable was unrelated to change in negative affect following cue exposure suggests that the present findings are unlikely to be a function of nicotine deprivation. This interpretation, however, is limited by the brief deprivation period prior to experimental sessions ( $M=28.3 \mathrm{~min} ; 98 \%$ had smoked within $90 \mathrm{~min}$ ) and by the fact that time since last cigarette was self-selected by participants rather than being experimentally manipulated.

In sum, these data provide further evidence for the existence of a negative affective pathway linking impulsivity and smoking. They also provide support for the conceptualization of impulsivity as a construct composed of multiple facets (Evenden, 1999; Whiteside \& Lynam, 2001) and suggest that assessing impulsivity as a unitary construct may mask the influence of individual facets. Our findings suggest that the negative affective pathway between impulsivity and smoking may be specific to urgency and sensation seeking. To the extent that smoking cues elicit negative affect in individuals who perceive smoking as an effective means of alleviating negative affect, such individuals could be disproportionately likely to smoke in response.

\section{References}

Arnett, P. A., \& Newman, J. P. (2000). Gray's three-arousal model: An empirical investigation. Personality \& Individual Differences, 28, 11711189.

Baker, T. B., Morse, E., \& Sherman, J. E. (1987). The motivation to use drugs: Psychobiological analysis of urges. In C. Rivers (Ed.), Nebraska Symposium on Motivation: Alcohol Use and Abuse: Vol. 34 (pp. $257-$ 323). Lincoln: University of Nebraska Press.

Carver, C. S. (2004). Negative affects derived from the Behavioral Approach System. Emotion, 4, 3-22.

Centers for Disease Control. (2005). Cigarette smoking among adultsUnited States, 2004. Morbidity \& Mortality Weekly Report, 54, 11211124.

Cooper, M. L., Agocha, V. B., \& Sheldon, M. S. (2000). A motivational perspective on risky behaviors: The role of personality and affect regulatory processes. Journal of Personality, 68, 1059-1088.

Cox, L. S., Tiffany, S. T., \& Christen, A. G. (2001). Evaluation of the brief questionnaire of smoking urges (QSU-brief) in laboratory and clinical settings. Nicotine \& Tobacco Research, 3, 7-16.

Doran, N., McChargue, D., \& Cohen, L. (2007). Impulsivity, selfdirectedness, and the reinforcing value of cigarette smoking. Addictive Behaviors, 32, 90-98.

Doran, N., McChargue, D., Spring, B., VanderVeen, J., Cook, J. W., \& Richmond, M. (2006). Effect of nicotine on negative mood among more impulsive smokers. Experimental \& Clinical Psychopharmacology, 14, 287-295.

Doran, N., Spring, B., \& McChargue, D. (2007). Effect of impulsivity on craving and behavioral reactivity to smoking cues. Psychopharmacology, 194, 279-288.

Doran, N., Spring, B., McChargue, D., Pergadia, M., \& Richmond, M. (2004). Impulsivity and smoking relapse. Nicotine \& Tobacco Research, 6, 641-647.

Emmons, R. A., \& Diener, E. (1986). Influence of impulsivity and sociability on subjective well-being. Journal of Personality and Social Psychology, 50, 1211-1215.

Evenden, J. (1999). Varieties of impulsivity. Psychopharmacology, 146, $348-361$.

Geist, C. R., \& Hermann, S. M. (1990). A comparison of the psychological characteristics of smokers, ex-smokers, and nonsmokers. Journal of Clinical Psychology, 46, 102-105.

Gibbons, R. D., Hedeker, D., Elkin, I., Waternaux, C., Kraemer, H. C., Greenhouse, J., et al. (1993). Some conceptual and statistical issues in analysis of longitudinal psychiatric data. Application to the NIMH Treatment of Depression Collaborative Research Program dataset. Archives of General Psychiatry, 50, 739-750.

Heatherton, T. F., Kozlowski, L. T., Frecker, R. C., \& Fagerström, K. O. (1991). The Fagerström Test for Nicotine Dependence: A revision of the 
Fagerström Tolerance Questionnaire. British Journal of Addiction, 86, $1119-1127$.

Hedeker, D., Flay, B. R., \& Petraitis, J. (1996). Estimating individual influences of behavioral intentions: An application of random-effects modeling to the theory of reasoned action. Journal of Consulting and Clinical Psychology, 64, 109-120.

Hedeker, D., \& Gibbons, R. D. (1997). Application of random-effects pattern-mixture models for missing data in longitudinal studies. Psychological Methods, 2, 64-78.

Hughes, J. R., \& Brandon, T. H. (2003). A softer view of hardening. Nicotine \& Tobacco Research, 5, 961-962.

Hussong, A. M., \& Chassin, L. (1994). The stress-negative affect model of adolescent drug use: Disaggregating negative affect. Journal of Studies on Alcohol, 55, 707-718.

Hutchison, K. E., Monti, P. M., Rohsenow, D. J., Swift, R. M., Colby, S. M., Gnys, M., et al. (1999). Effects of naltrexone with nicotine replacement on smoking cue reactivity: Preliminary results. Psychopharmacology, 142, 139-143.

Irvin, J. E., \& Brandon, T. H. (2000). The increasing recalcitrance of smokers in clinical trials. Nicotine \& Tobacco Research, 2, 79-84.

Irvin, J. E., Hendricks, P. S., \& Brandon, T. H. (2003). The increasing recalcitrance of smokers in clinical trials II: Pharmacotherapy trials. Nicotine \& Tobacco Research, 5, 27-35.

Jenks, R. J. (1992). Attitudes, perceptions, and risk-taking behaviors of smokers, ex-smokers, and nonsmokers. Journal of Social Psychology, $132,569-575$.

Joireman, J., Anderson, J., \& Strathman, A. (2003). The aggression paradox: Understanding links among aggression, sensation seeking, and the consideration of future consequences. Journal of Personality and Social Psychology, 84, 1287-1302.

Kambouropoulos, N., \& Staiger, P. K. (2001). The influence of sensitivity to reward on reactivity to alcohol-related cues. Addiction, 96, 11751185.

Kassel, J. D., Shiffman, S., Gnys, M., Paty, J., \& Zettler-Segal, M. (1994). Psychosocial and personality differences in chippers and regular smokers. Addictive Behaviors, 19, 565-575.

King, K. M., \& Chassin, L. (2004). Mediating and moderated effects of adolescent behavioral undercontrol and parenting in the prediction of drug use disorders in emerging adulthood. Psychology of Addictive Behaviors, 18, 239-249.

Mann, L. M., Chassin, L., \& Sher, K. J. (1987). Alcohol expectancies and the risk of alcoholism. Journal of Consulting and Clinical Psychology, 55, 411-417.

Marlatt, G. A., \& Gordon, J. R. (1985). Relapse prevention. New York: Guilford Press.

Martin, L. E., \& Potts, G. F. (2004). Reward sensitivity in impulsivity. NeuroReport, 15, 1519-1522.

Mitchell, S. H. (2004). Measuring impulsivity and modeling its association with cigarette smoking. Behavioral \& Cognitive Neuroscience Reviews, 3, 261-275.

Patton, J. H., Stanford, M. S., \& Barratt, E. S. (1995). Factor structure of the Barratt Impulsiveness Scale. Journal of Clinical Psychology, 51, $768-774$.

Payne, T. J., Smith, P. O., Sturges, L. V., \& Holleran, S. A. (1996). Reactivity to smoking cues: Mediating roles of nicotine dependence and duration of deprivation. Addictive Behaviors, 21, 139-154.
Powell, J., Bradley, B., \& Gray, J. (1992). Classical conditioning and cognitive determinants of subjective craving for opiates: An investigation of their relative contributions. British Journal of Addiction, 87, $1133-1144$

Sayette, M. A., \& Hufford, M. R. (1994). Effects of cue exposure and deprivation on cognitive resources in smokers. Journal of Consulting and Clinical Psychology, 103, 812-818.

Sher, K. J., \& Levenson, R. W. (1982). Risk for alcoholism and individual differences in the stress response dampening effect of alcohol. Journal of Abnormal Psychology, 91, 350-367.

Siegel, S. (1999). Drug anticipation and drug addiction. The 1998 H. David Archibald Lecture. Addiction, 94, 1113-1124.

Siegel, S. (2005). Drug tolerance, drug addiction, and drug anticipation. Current Directions in Psychological Science, 14, 296-300.

Spitzer, R. L., Williams, J. B., Gibbon, M., \& First, M. B. (1992). The Structured Clinical Interview for DSM-III-R (SCID). History, rationale, and description. Archives of General Psychiatry, 49, 624-629.

Steiger, J. H. (1980). Tests for comparing elements of a correlation matrix. Psychological Bulletin, 87, 245-251.

Tiffany, S. T., Cox, L. S., \& Elash, C. A. (2000). Effect of transdermal nicotine patches on abstinence-induced and cue-elicited craving in cigarette smokers. Journal of Consulting and Clinical Psychology, 68, 233-240.

Verbeke, G., \& Mohlenberghs, G. (2000). Linear mixed models for longitudinal data. New York: Springer.

Warner, K. E., \& Burns, D. M. (2003). Hardening and the hard-core smoker: Concepts, evidence, and implications. Nicotine \& Tobacco Research, 5, 37-48.

Watson, D., Clark, L. A., \& Tellegen, A. (1988). Development and validation of brief measures of positive and negative affect: The PANAS scales. Journal of Personality and Social Psychology, 54, 1063-1070.

Whiteside, S. P., \& Lynam, D. R. (2001). The Five Factor Model and impulsivity: Using a structural model of personality to understand impulsivity. Personality \& Individual Differences, 30, 669-689.

Whiteside, S. P., Lynam, D. R., Miller, J. D., \& Reynolds, S. K. (2005). Validation of the UPPS Impulsive Behaviour Scale: A four-factor model of impulsivity. European Journal of Personality, 19, 559-574.

Williams, A. F. (1973). Personality and other characteristics associated with cigarette smoking among young teenagers. Journal of Health \& Social Behavior, 14, 374-380.

Williams, J. B. W., Gibbon, M., First, M. B., Spitzer, R. L., Davies, R. M., \& Borus, J. (1992). The Structured Clinical Interview for DSM-III-R (SCID). Multisite test-retest reliability. Archives of General Psychiatry, 49, 630-636.

Zelenski, J. M., \& Larsen, R. J. (1999). Susceptibility to affect: A comparison of three personality taxonomies. Journal of Personality, 67, 761-791.

Zuckerman, M., Joireman, J., Kraft, M., \& Kuhlman, D. M. (1999). Where do emotional and motivational traits fit within three-factor models of personality? Personality \& Individual Differences, 26, 487-504.

Received May 10, 2007

Revision received December 1, 2007 Accepted December 3, 2007 